\title{
NPUST Sustainable Operations and the Development of Circular Economies
}

\author{
.H. $\operatorname{Tai}^{1,}{ }^{*}$, P.M $L i^{2}$ \\ ${ }^{1}$ President, National Pingtung University of Science and Technology, Taiwan \\ ${ }^{2}$ Dean, Office of International Affairs, National Pingtung University of Science and Technology, Taiwan \\ *corresponding author: president@mail.npust.edu.tw
}

Article Info

Received:

15 March 2021

Accepted:

25 May 2021

Published:

1 August 2021

DOI:

Presented in The $6^{\text {th }}$ International (Virtual) Workshop on UI GreenMetric World University Rankings (IWGM 2020)

\begin{abstract}
The National Pingtung University of Science and Technology was established as an agricultural institution in 1924. With a true appreciation for the environment, the university is dedicated to the pursuit of technology and practices that are sustainable, eco-friendly and environmentally sound. The university has already earned a reputation for "being Green" as a result of its approach to sustainable operations and circular economies. The university is actively working to make its campus Greener and healthier through simple measures, such as lending out free bicycles to students, and complex measures, such as developing water treatment and recycling systems designed to conserve water and restore eco-systems. Additionally, the university is working to raise environmental awareness among its students and is actively investing in the research and development of technologies that will be able to help businesses operate more sustainably in the future.
\end{abstract}

\section{Keyword:}

Water treatment and recycling, creation of waterscape, zero emissions

\section{Introduction}

The National Pingtung University of Science and Technology was established in 1924 as an agricultural institution. For almost a century, this educational institution has been making valuable contributions to the advancement of Taiwan's agricultural sectors through projects funded by various governmental agencies and private sectors. The university is well committed to the development and execution of projects that strengthen its "Green" identity, and it has established related measures involving teaching, research, university development, student welfare and other valued objectives. Such goals serve as the basis for the initiation of new policies; however, the execution of related projects requires proper planning, enforcement, and funding to reach the point of maturity and recompense. With these underlying considerations in place, the foremost issue that must continuously be raised are directed at the need for a rolling-wave style management approach for sustainability in all various dimensions, including on-going evaluations that continuously provide the feedback 
necessary for future adjustments. Currently the university has three over-arching approaches dedicated to the themes of sustainability and care for the environment. These approaches involve both the adoption of practices that can have an immediate impact on air quality and water conservation, and the investment in research and education that will allow for much broader out-reaching sustainable operations.

\section{Approaches}

\subsection{Water conservation program implementation}

NPUST water sources include groundwater, mountain spring water and rain water. $100 \%$ of recycled water is treated at a sewage treatment plant and used for non-contact purposes such as watering vegetation or flushing toilets. Furthermore, the water recycling program would play an important role in stabilizing the strata and slowing down subsidence $[1,2]$.

Water pollution control measures and education campaigns have been adopted by the university to promote the awareness for environmental care and sustainability; moreover, waste water management techniques have been used for ecological restoration purposes, including the creation of a waterscape that is home to a variety of plant and aquatic lifeforms. The design not only offers a living space for plant and animal life, but also helps increase biodiversity and provides a very natural setting for ecological research, education and the promotion thereof. The restoration area also gives teachers, students, local residents and visitors a space for relaxation and recreation.

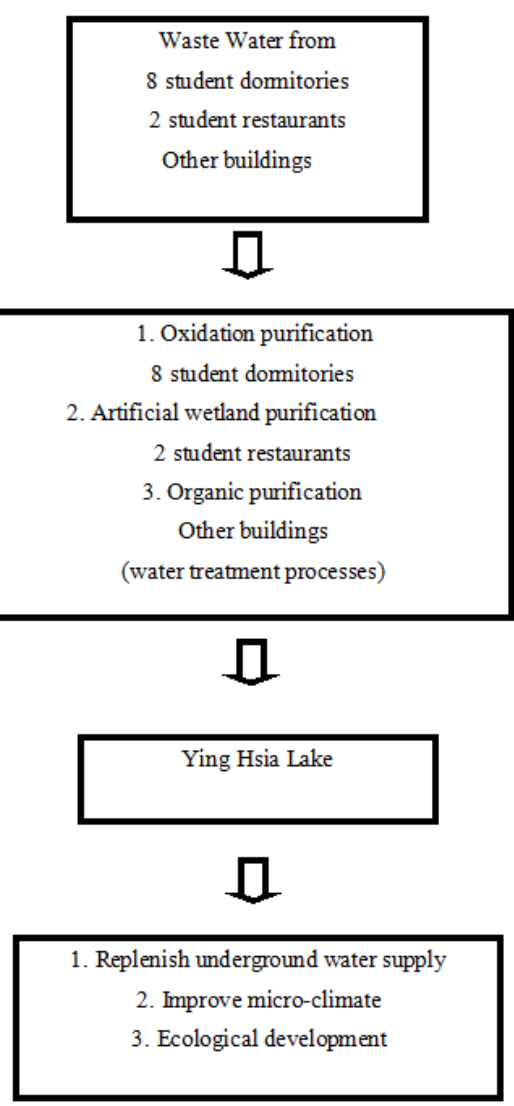

Figure 1. NPUST domestic waste water treatment and recycling 


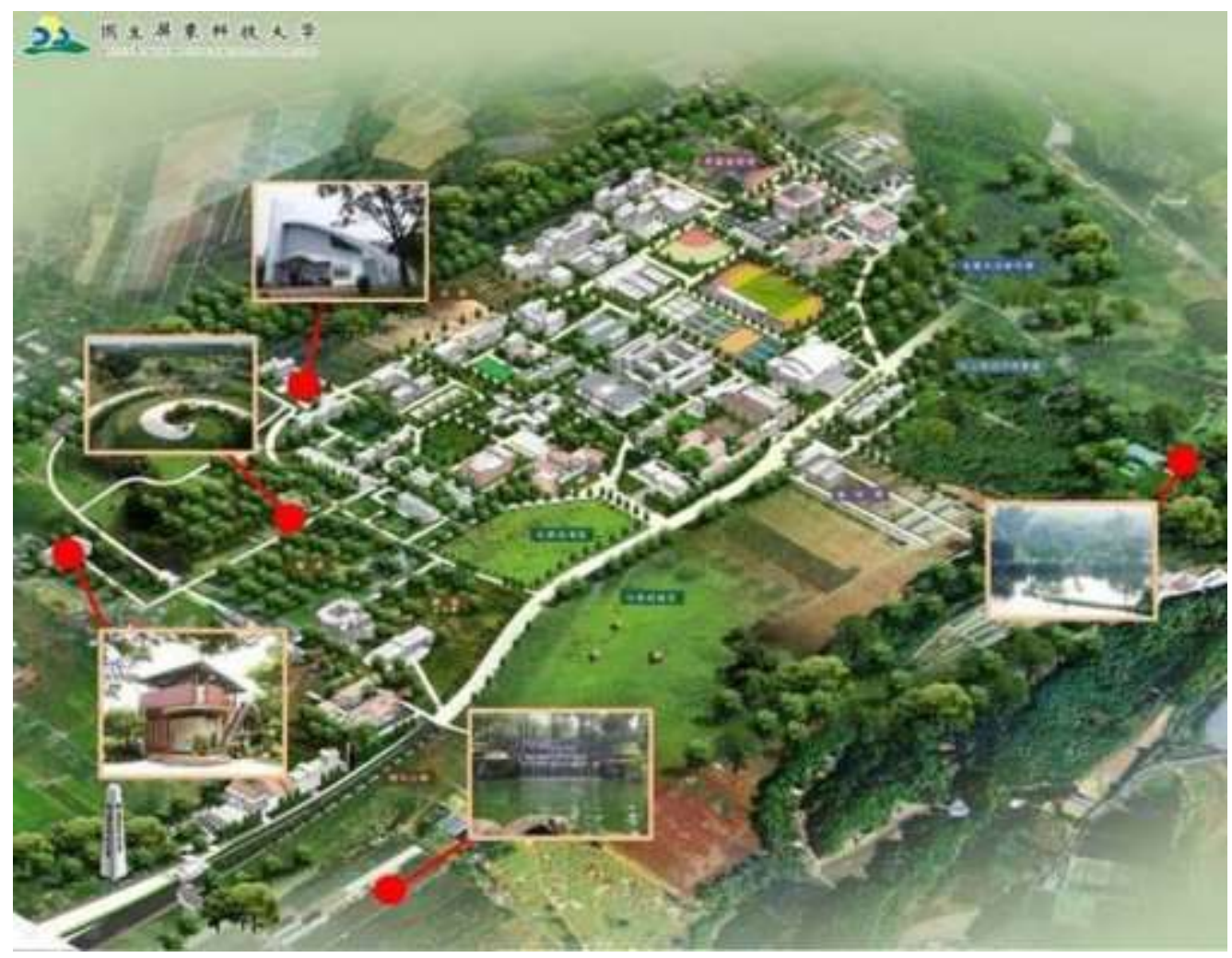

Figure 2. NPUST waste water recycle processing areas

\subsection{Zero Emission Vehicles}

As part of its efforts to cooperate with the Green Energy Policy and accelerate the reduction of carbon dioxide emissions, the university has established a number of related measures on campus $[3,4]$. In the past, NPUST freshmen wholly relied on gas-powered motorcycles to commute both inside and outside the campus area. However, in recent years, the university has set a goal to reduce the use of gasoline motorcycles by providing subsidies for an on-campus/off-campus electric bus system, offering leasing programs for electric motorcycles, and lending out bicycles free of charge [5].

NPUST and China Motors are jointly promoting means of "green transportation" on campus, including electric vehicles and bicycles which can be rented out or bought through one of three preferential schemes created for students. Electric vehicle charging stands have also been installed at the dorms, Administrative Building, and Comprehensive Building on campus for electric vehicle commuters to charge their batteries free of charge. Service stations have also been set up at the school to provide related consultation and simple maintenance services. Furthermore, battery exchange stations have been installed to provide additional options for users. In August 2017, a total of 39 electric bicycles/vehicles were rented by teaching/ administrative units for various official duties. At present, the number of electric bicycles/motorcycles rented by students is about 300; there are also 20 privately owned electric bicycles/motorcycles in use.

In order to reduce the number of motorcyclists and reduce air pollution, NPUST has applied to the Kaohsiung City Government Environmental Protection Bureau for more than 200 C-BIKE bicycles. These are provided to the students for use at no charge and can be borrowed from various stations around campus. Currently, 187 bikes have been lent out and another 450 to 500 private bicycles are in use. 


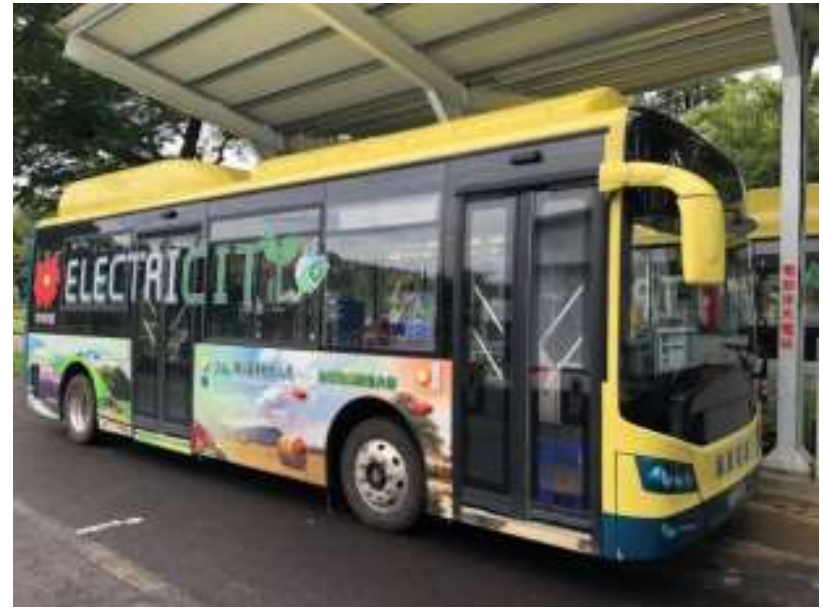

Figure 3. Electric bus

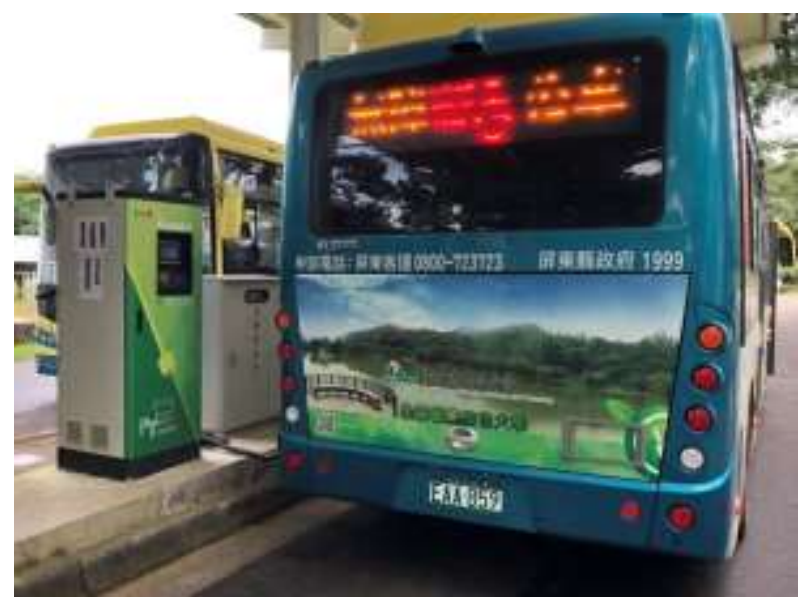

Figure 4. Electric Bus charging at the station

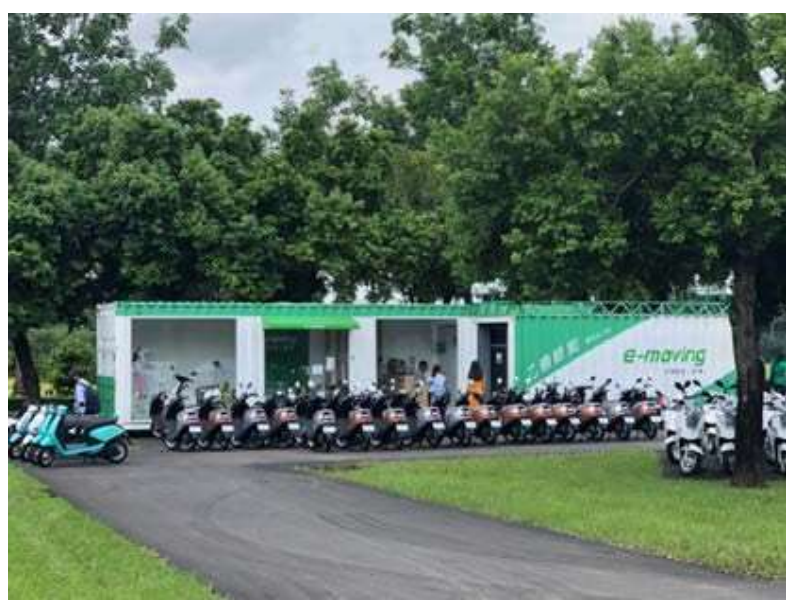

Figure 5. Electric bicycle/motorcycle charging station 


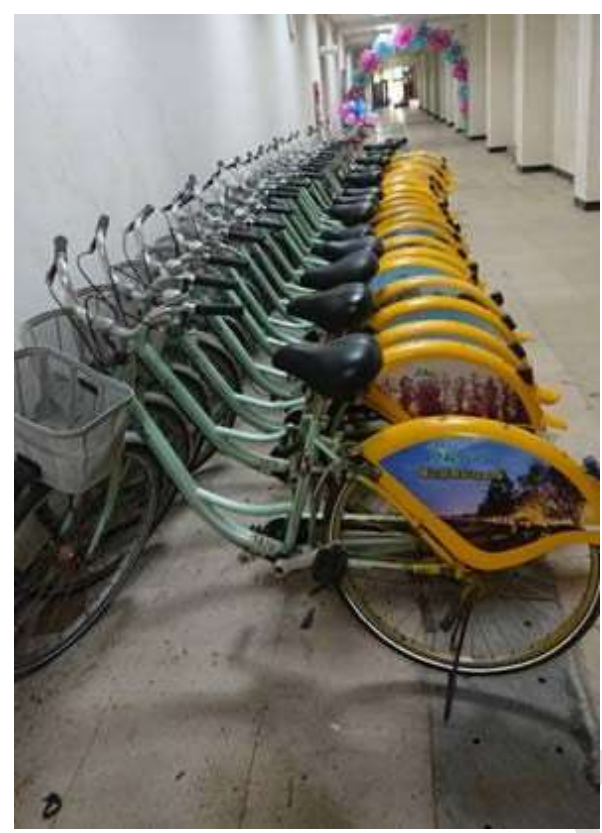

Figure 6. Bicycles

\subsection{Education}

The two approaches mentioned above are practical in application and have immediate effects; however, their contributions are inherently limited to the campus and the nearby community [6]. Thus, in an effort to create positive benefits that spread far-and-wide, NPUST has also dedicated itself to a third approach, which is oriented towards R\&D and education. The university recognizes that by developing Green and sustainable technologies that can be used by industries as economically viable substitutions for those which are more taxing on the environment, it has a chance to make contributions that can be shared by the world. Additionally, by raising awareness and providing education on the nature of relevant environmental and sustainability issues, students and the general public will stand in better positions to make their own contributions in ways transmittable and transferable -once they start looking at the world with new perspectives. Members of society will undoubtedly discover new ways of overcoming related challenges in their local communities. Currently, the university is making an effort to encourage faculty members to incorporate topics related to the environment or sustainability into their course materials. The statistical information related to these courses is presented in Table 1 below.

Table 1. Statistics of courses related to environment and sustainability

\begin{tabular}{lcc}
\hline Year & Number & Percentage \\
\hline 2013 & 1731 & $34.46 \%$ \\
2014 & 1988 & $39.78 \%$ \\
2015 & 2727 & $50.68 \%$ \\
2016 & 2731 & $50.82 \%$ \\
2017 & 2781 & $51.75 \%$ \\
\hline
\end{tabular}




\section{Summary}

National Pingtung University of Science and Technology set our sights on seeking for real solutions to real problems. To share those solutions with the global society, resources are invested towards the development of technologies that hold high potential to reach farther and have more resonant impact. By adopting green and sustainable practices that address issues related to air quality, water conservation, ecosystem restoration and environmental protection, the university aims to play a leading role in materializing the concept of sustainable development, and in turn prompt tangible changes amongst students and communities. With care and concern for future generations, NPUST vows to keep up with its current pace and continue to initiate more projects that support sustainable development goals and help create a better world for tomorrow.

\section{References}

1. Petersen, J.E., et al., 2015. Electricity and Water Conservation on College and University Campuses in Response to National Competitions among Dormitories: Quantifying Relationships between Behavior, Conservation Strategies and Psychological Metrics. PLoS One. 10(12): p. e0144070.

2. Marinho, M., M.d.S. Gonçalves, and A. Kiperstok, 2014. Water conservation as a tool to support sustainable practices in a Brazilian public university. Journal of Cleaner Production, 62: p. 98-106.

3. Goodrow, B., G. Scherzer, and J. Florence, 2004. An application of multidisciplinary education to a campus-community partnership to reduce motor vehicle accidents. Educ Health (Abingdon), 17(2): p. 152- 62.

4. Stone, L.M. and C.W. Runyan, 2005. High school off-campus lunch policies and adolescent motor vehicle crash risks. J Adolesc Health, 36(1): p. 5-8.

5. Akti, S. and H.B. Celikoglu, 2019. An Integrated Decision Making Framework For Vehicle Selection in Shuttle Services: Case of A University Campus. in 2019 6th International Conference on Models and Technologies for Intelligent Transportation Systems (MT-ITS).

6. Weinberg, A.E., et al., 2020. Looking inward, outward, and forward: Exploring the process of transformative learning in teacher education for a sustainable future. Sustainability Science, 15(6): p. 1767-1787. 